\title{
Canonical Correlation Analysis for Estimation of Relationship between Anthropometric Measurements and Office Furniture Measurements in Public Institution
}

\author{
Adu, G. \\ Department of Interior Design and Materials Technology \\ Faculty of Built and Natural Environment \\ Kumasi Technical University \\ Ghana \\ Adu, S. \\ Department of Forest Resources Technology \\ Faculty of Renewable Natural Resources \\ Kwame Nkrumah University of Science and Technology \\ Ghana \\ Asare, K.P. \\ Department of Mathematics and Statistics \\ Faculty of Applied Sciences and Technology \\ Kumasi Technical University \\ Ghana \\ Darkwa, N.A \\ Department of Wood Science and Technology \\ Faculty of Renewable Natural Resources \\ Kwame Nkrumah University of Science and Technology \\ Ghana
}

\begin{abstract}
Canonical correlation analysis (CCA) was adopted to develop relationships between anthropometric measurements and furniture measurements to enhance some healthy sitting posture. Estimation of relationship between two groups of measurements in public institutions is achieved through CCA. The objective of this research was to apply canonical correlation analysis to establish the relationship between human body measurements (Anthropometric Measurements) such as popliteal to floor height, buttock to popliteal length, elbow to seat height, sitting shoulder height, knee height and width of bitrochanter and furniture measurements such as seat height, seat depth, armrest height, backrest height, desk clearance and seat width in public institutions. In this study, canonical correlation analysis was applied to incorporate many variables within a single research analysis to develop relationships between those variables. The results showed that six canonical correlations were obtained $(0.830,0.666,0.350,0.283,0.173$ and 0.056). Among the estimated correlation coefficients, the first three pairs were significant ( $p<0.001$ in each). In the first pair of canonical variables, the estimated relationships were between seat width and width of bitrochanter and, seat width and sitting shoulder height. For the second pair of canonical variables, the relationship were between desk clearance and width of bitrochanter; seat width and width of bitrochanter; and between desk clearance and seat width within the furniture variables. Finally, the third pair of canonical variables was between seat height and popliteal to floor height.
\end{abstract}

Keywords: Canonical correlation coefficient, Canonical variable, Anthropometry, Furniture measurements, Public institution

\section{Introduction}

The purpose of this study was to establish the various relationships between measurements of workers' body and furniture patronized. 
Canonical correlation analysis (CCA) was used to develop relationships between anthropometric measurements (popliteal to floor height, buttock to popliteal length, elbow to seat height, sitting shoulder height, knee height and width of bitrochanter) and furniture measurements (seat height, seat depth, armest height, backrest height, desk clearance and seat width) to enhance some healthy sitting posture (Garcia-Acosta and Lange-Morales, 2007). CCA reported by Hotellings (1935) as cited in Thompson (1984) is a way of telling the union between two (2) sets of variables by reporting orthogonal (i.e. uncorrelated) canonical variables that are maximally correlated. Estimation of relationship between two groups of measurements in public institutions is achieved through multivariate correlation (Johnson and Wichern, 2007). CCA allows scientific researchers to add several variables in a single analysis (Bartoszynski and Niewiadomska-Bugaj, 2008). Thus, in analyzing single or multiple variables one at a time in many studies are right to reach favourable and significant statistical conclusions (Sheskin, 2000). Apart from the existence of relationship that is reported, the strength of the relationship is not seen (Wilkinson \& APA Task Force on Statistical Inference, 1999). CCA having the Structure coefficients are critical for deciding which variables are useful for the function (Courville \& Thompson, 2001). The applications of CCA to address the associations between those measurements were not founded in the literature according to our knowledge. However, this study seeks to establish the relationships between those measurements in public institutions with the help of CCA.

Anthropometric data is used in workstation, equipment and furniture design (Pheasant, 2003; Del Prado-Lu, 2007). Poorly manufactured office furniture brings about discomfort, body pain, inefficiency, delay and wastage (Abeysekera, 1985). Many countries have been able to gather measurements on civilians, military personnel, students and workers body (Bolstadet al., 2001; Wang et al., 2002).

The objective was to apply CCA to examine the relationship between measurements of administrative staff and furniture measurements in public institutions. The methodology of this study is to discover what anthropometric dimensions relate with which furniture dimensions. Estimation of relationship between two groups of measurements in public institutions is achieved through CCA. Therefore, CCA will develop the relationships between anthropometric measurements and furniture measurements. Data recorded include six anthropometric variables and six furniture variables which were obtained from 310 office workers in three public institutions. Through survey method, the data for anthropometric variables and furniture variables were collected.

\section{Materials and Methods}

Canonical Correlation measures the relationship between two sets of variables, and how best the linear combinations of anthropometric measurements relate to the linear combinations of the furniture measurements. The hypothesis is stated as whether or not there was significance when the analysis is considered together in terms of relationship. Canonical correlation was performed on measures of anthropometric data with measures of furniture data (Adu, 2017).

Anthropometric and furniture measurements on sample of 310 users of the Ghana made office furniture (chairs and desks) at their usual places in their various institutions at the time of the survey were simultaneously taken by the researchers and their recording assistants. Canonical analysis elements included composite of dependent variables (dependent canonical variates) and composite of independent variables (independent canonical variates). The measured anthropometric measurements become the first variable set (X - variable set) and furniture measurements become the second variable set $(\mathrm{Y}-$ variable set).

According to Gunderson and Muirhead (1997), the canonical variables for the linear combination of the X variable set and the linear combination of the variable in $\mathrm{Y}$ - variable set are $\mathrm{L}$ and $\mathrm{M}$ respectively, and these two (2) canonical variables is maximized. $\mathrm{L}$ and $\mathrm{M}$ represent the largest association of the six (6) different anthropometric measurements and the six (6) furniture measurements observed variables. Subsequently, the other pairs are maximized and not correlated with their previous ones (Johnson and Wichem, 2002).

Using the 2 matrices $X$ and $Y$ of order $n \times p$ and $n \times q$ respectively, the $j^{\text {th }}$ column of the matrix $X$ is represented by $\mathrm{X}^{\mathrm{j}}$, and the $\mathrm{k}^{\text {th }}$ column of $\mathrm{Y}$ is represented by $\mathrm{Y}^{\mathrm{k}}$. Notwithstanding the loss of generality, it is assumed that the columns of $\mathrm{X}$ and $\mathrm{Y}$ are standardized (as mean is zero and variance is one). In this study, $\mathrm{p}=\mathrm{q}$ (in other words, the 2 groups contain equal number of variables). Then we represent $S_{\mathrm{xx}}$ and $S_{\mathrm{yy}}$ as sample covariance matrices for the 2 variable sets $X$ and $Y$ respectively, and $S_{x y}=S_{y x}^{T}$ as the sample cross-covariance matrix between $X$ and $Y$. A vector or a matrix ' $A$ ' which is transposed is expressed symbolically as $A^{T}$. 
For this study, the two vectors obtained from the first stage of CCA included: $a_{1}=\left(a_{1,1}, a_{1,2}, a_{1,3}, a_{1,4}, a_{1,5}\right.$, $\left.a_{1,6}\right)^{\mathrm{T}}$ and $b_{1}=\left(b_{1,1}, b_{1,2}, b_{1,3}, b_{1,4}, b_{1,5}, b_{1,6}\right)^{\mathrm{T}}$ that brought about the highest correlation when the 2 variates following are put together

$\mathrm{L}_{1}=\mathrm{X} a_{1}=a_{1,1} X_{1}+a_{1,2} X_{2}+a_{1,3} X_{3}+a_{1,4} X_{4}+a_{1,5} X_{5}+a_{1,6} X_{6} \quad$ and

$\mathrm{M}_{1}=\mathrm{Y} b_{1}=b_{1,1} Y_{1}+b_{1,2} Y_{2}+b_{1,3} Y_{3}+b_{1,4} Y_{4}+b_{1,5} Y_{5}+b_{1,6} Y_{6}$

Assuming that vectors $a_{1}$ and $b_{1}$ are normalized so that $\operatorname{var}\left(L_{1}\right)=\operatorname{var}\left(M_{1}\right)=1$.

Furthermore, the challenge is about solving $R_{1}=\operatorname{cor}\left(L_{1}, M_{1}\right)=\max _{a, b} \operatorname{cor}\left(X_{a}, Y_{b}\right)$, relative to the constraint $\operatorname{var}(\mathrm{Xa})=\operatorname{var}(\mathrm{Yb})=1$.

Thus, $L_{1}$ and $M_{1}$ stand for the first canonical variables and $R_{1}$ stands for the initial canonical correlation.

Systematic order canonical variates and canonical correlations can be obtained as a step by step method.

For $\mathrm{s}=1, \ldots, 6$, an individual without restrictions is able to obtain positive correlations $R_{1} \geq R_{2} \geq \cdots \geq R_{6}$ with additional vectors $\left(a_{1}, b_{1}\right), \ldots,\left(a_{6}, b_{6}\right)$, by maximizing

$R_{S}=\operatorname{cor}\left(L_{s}, M_{s}\right)=\max _{a^{s} b^{s}} \operatorname{cor}\left(\mathrm{X} a^{S}, \mathrm{Y} b^{s}\right)$ subject to $\operatorname{var}\left(\mathrm{X} a^{S}\right)=\operatorname{var}\left(\mathrm{Y} b^{S}\right)=1$, under the additional restriction

$\operatorname{cor}\left(L^{s}, L^{t}\right)=\operatorname{cor}\left(M^{s}, M^{t}\right)=0$ for $1 \leq \mathrm{t}<\mathrm{s} \leq 6$.

All the calculations were done to investigate the associations that exist between the two sets of the measurements. The analysis was run in SPSS version 21 using the CANCORR procedure.

\section{Results}

\section{The effect size of the relationship between anthropometric variables and furniture variables}

The study reported that there was a relationship between the two (2) sets of variables. Wilks' $\lambda$ of $0.135, F$ (36, $1311)=21.02$ at $p=0.000$ (Table 1). First five canonical variables were significant (Table 2). Standardized canonical coefficients (canonical weights) and canonical loadings (structure coefficients) with their communality coefficients $\left(h^{2}\right)$ were given for the first three pairs of canonical variables $\left(\mathrm{L}_{1}\right.$ and $\left.\mathrm{M}_{1}\right),\left(\mathrm{L}_{2}\right.$ and $\left.\mathrm{M}_{2}\right)$ and $\left(\mathrm{L}_{3}\right.$ and $\mathrm{M}_{3}$ ) in Tables 3 and 4, respectively.

Table1. Multivariate tests of significance of relationship between Anthropometric Variable Set and Furniture Variable Set

\begin{tabular}{llllll}
\hline Test & Value & F & Hypo. Df & Error Df & $p$-value \\
\hline Pillais & 1.36770 & 14.91027 & 36.00 & 1818.00 & 0.000 \\
Hotellings & 3.27096 & 26.92483 & 36.00 & 1778.00 & 0.000 \\
Wilks & 0.13523 & 21.02408 & 36.00 & 1311.37 & 0.000 \\
Roys & 0.68893 & & & & \\
\hline
\end{tabular}

$P<0.05$ for significance; $\mathrm{Df}=$ Degree of Freedom, $\mathrm{F}=$ Test statistic for multiple variables

Table 2 Summary results for the canonical correlation analysis between linear combinations of the anthropometric variable set and furniture variable set

\begin{tabular}{|c|c|c|c|c|c|c|}
\hline $\begin{array}{l}\text { Pair of canonical } \\
\text { variable }\end{array}$ & $\begin{array}{l}\text { Canonical } \\
\text { correlation }\end{array}$ & $\begin{array}{l}\text { Squared } \\
\text { correlation }\end{array}$ & canonical & Eigenvalue & Df & $\begin{array}{l}p \\
\text { value }\end{array}$ \\
\hline $\mathrm{L}_{1} \mathrm{M}_{1}$ & 0.830 & 0.689 & & 2.215 & 36 & $0.000^{*}$ \\
\hline $\mathrm{L}_{2} \mathrm{M}_{2}$ & 0.666 & 0.443 & & 0.795 & 25 & $0.000^{*}$ \\
\hline $\mathrm{L}_{3} \mathrm{M}_{3}$ & 0.350 & 0.123 & & 0.140 & 16 & $0.000^{*}$ \\
\hline $\mathrm{L}_{4} \mathrm{M}_{4}$ & 0.283 & 0.080 & & 0.087 & 9 & $0.000^{*}$ \\
\hline $\mathrm{L}_{5} \mathrm{M}_{5}$ & 0.173 & 0.030 & & 0.301 & 4 & 0.000 * \\
\hline $\mathrm{L}_{6} \mathrm{M}_{6}$ & 0.560 & 0.003 & & 0.003 & 1 & $0.331^{\mathrm{ns}}$ \\
\hline
\end{tabular}

*Significant at $p$-value $<0.05 ; \mathrm{ns}=$ Not Significant; $\mathrm{Df}=$ Degree of Freedom 
Table 3 Standardized canonical coefficients for canonical variables of the linear combinations of the anthropometric variable set and Furniture variable set

\begin{tabular}{|c|c|c|c|c|c|c|c|c|c|c|c|c|c|}
\hline & \multicolumn{6}{|c|}{$\mathrm{X}$-variable set } & & \multicolumn{6}{|c|}{ Y-variable set } \\
\hline & PFH & BPL & ESH & SSH & $\mathrm{KH}$ & WoB & & SH & SD & $\mathrm{AH}$ & $\mathrm{BH}$ & DC & SW \\
\hline $\mathrm{L}_{1}$ & 0.07 & 0.03 & -0.05 & -0.96 & -0.91 & 0.16 & $\mathrm{M}_{1}$ & -0.12 & -0.15 & 0.12 & -0.10 & -0.61 & 1.06 \\
\hline $\mathrm{L}_{2}$ & 0.27 & 0.21 & 0.23 & -0.44 & -0.11 & -0.87 & $\mathrm{M}_{2}$ & 0.01 & 0.09 & -0.14 & 0.05 & 0.81 & 0.37 \\
\hline $\mathrm{L}_{3}$ & -1.06 & -0.10 & -0.12 & -0.40 & 0.26 & -0.63 & $\mathrm{M}_{3}$ & -0.81 & -0.20 & -0.26 & -0.29 & 0.09 & 0.36 \\
\hline
\end{tabular}

$\mathrm{PFH}=$ Popliteal to floor height; BPL $=$ Buttock to popliteal length; ESH $=$ Elbow to seat height; SSH $=$ Sitting shoulder height; $\mathrm{KH}=$ Knee height; $\mathrm{WoB}=$ Width of bitrochanter; $\mathrm{SH}=$ Seat height; $\mathrm{SD}=$ Seat depth; $\mathrm{AH}=$ Armrest height; $\mathrm{BH}=$ Backrest height DC $=$ Desk clearance; $\mathrm{SW}=$ Seat width

Table 4 Canonical loadings of the original variables with their canonical variables of the linear combinations of the anthropometric variable set and furniture variable set

\begin{tabular}{|c|c|c|c|c|c|c|c|c|c|c|c|c|c|}
\hline & \multicolumn{6}{|c|}{$\begin{array}{l}\text { X-variable } \\
\text { set }\end{array}$} & & \multicolumn{6}{|c|}{ Y-variable set } \\
\hline & PFH & BPL & ESH & SSH & $\mathrm{KH}$ & WoB & & SH & SD & $\mathrm{AH}$ & $\mathrm{BH}$ & DC & SW \\
\hline $\mathrm{L}_{1}$ & 0.20 & 0.05 & -0.01 & -0.99 & 0.49 & $\underline{0.51}$ & $\mathrm{M}_{1}$ & 0.09 & 0.24 & 0.27 & 0.19 & -0.35 & $\underline{0.78}$ \\
\hline $\mathrm{L}_{2}$ & 0.44 & 0.33 & 0.35 & -0.11 & 0.00 & -0.79 & $\mathrm{M}_{2}$ & 0.23 & 0.30 & 0.30 & 0.23 & $\underline{0.90}$ & 0.62 \\
\hline $\mathrm{L}_{3}$ & $\underline{-0.80}$ & -0.33 & -0.05 & -0.08 & -0.28 & $\overline{-0.26}$ & $\mathrm{M}_{3}$ & $\underline{-0.86}$ & -0.50 & -0.32 & -0.53 & $\overline{0.10}$ & $\overline{-0.12}$ \\
\hline$h^{2}(\%)$ & $\overline{85.59}$ & 21.74 & 12.11 & 99.36 & 32.11 & 94.41 & $h^{2}(\%)$ & $\overline{79.17}$ & 40.41 & 26.56 & 37.43 & 94.46 & 99.58 \\
\hline
\end{tabular}

Canonical loadings $\geq 145$ are underlined; $h^{2}=$ Square communality coefficients $\geq 45 \%$ are underlined; PFH = Popliteal to floor height; BPL = Buttock to popliteal length; ESH = Elbow to seat height; $\mathrm{SSH}=\mathrm{Sitting}$ shoulder height; $\mathrm{KH}=$ Knee height; $\mathrm{WoB}=$ Width of bitrochanter; $\mathrm{SH}=$ Seat height; $\mathrm{SD}=$ Seat depth; $\mathrm{AH}=\mathrm{Armrest}$ height; $\mathrm{BH}=$ Backrest height; $\mathrm{DC}=$ Desk clearance; $\mathrm{SW}=$ Seat width

\section{Discussion}

The symbol " $\lambda$ " is called lambda. Wilks' $\lambda$ is by far the most common indicator used in determining whether there is significant degree of relationship between the sets of variables (or effect size). The unseen strength of the relationship conforms to what was reported by Wilkinson \& APA Task Force on Statistical Inference (1999). But, by taking $(1-0.135=0.865)$, large effect size of $86.50 \%$ was found for the full model (Table 1$)$. The calculation unraveled the magnitude of the relationship and further revealed the amount of variance not shared between the variable sets.

The number of canonical variables is dependent on variables available in the smaller set, of which is six (since both anthropometric variables and furniture variables have equal number of variables). This study only interpreted the canonical variable pairs that explained squared correlation value between the canonical variable pairs. Thus, the pairs of canonical variables (variates) that explained a reasonable amount of variance (squared correlation), that are $10.00 \%$ or more are interpreted. From the results, the first three canonical variable pairs $\left(\mathrm{L}_{1} \mathrm{M}_{1}, \mathrm{~L}_{2} \mathrm{M}_{2}\right.$, and $\mathrm{L}_{3} \mathrm{M}_{3}$ ) are of importance since they explained squared correlations of $68.90 \%, 44.30 \%$ and $12.30 \%$ respectively. However, the fourth, fifth, and sixth canonical variable pairs reported values below $10,00 \%$ as squared correlation of $8.00 \%, 3.00 \%$, and $0.30 \%$, respectively.

The magnitudes of the canonical coefficients signify their relative contributions to the correlated variates. That is, these coefficients indicate the effect of the anthropometric variables on the furniture variables. Therefore, the canonical variates $\left(\mathrm{L}_{1} \mathrm{M}_{1}, \mathrm{~L}_{2} \mathrm{M}_{2}\right.$ and $\left.\mathrm{L}_{3} \mathrm{M}_{3}\right)$ representing the optimal linear combinations of dependent and independent variables can be defined by using the standardized canonical coefficients given in Table 3 as:

$$
\begin{aligned}
& \mathrm{M}_{1}=-0.12(\mathrm{SH})-0.15(\mathrm{SD})+0.12(\mathrm{AH})-0.10(\mathrm{BH})-0.61(\mathrm{DC})+1.06(\mathrm{SW}) \\
& \mathrm{M}_{2}=0.01(\mathrm{SH})+0.09(\mathrm{SD})-0.14(\mathrm{AH})+0.05(\mathrm{BH})+0.81(\mathrm{DC})+0.37(\mathrm{SW}) \\
& \mathrm{M}_{3}=-0.81(\mathrm{SH})-0.20(\mathrm{SD})-0.26(\mathrm{AH})-0.29(\mathrm{BH})+0.09(\mathrm{DC})+0.36(\mathrm{SW}) \\
& \mathrm{L}_{1}=0.07(\mathrm{PFH})+0.03(\mathrm{BPL})-0.05(\mathrm{ESH})-0.96(\mathrm{SSH})-0.91(\mathrm{KH})+0.16(\mathrm{WoB}) \\
& \mathrm{L}_{2}=0.27(\mathrm{PFH})+0.21(\mathrm{BPL})+0.23(\mathrm{ESH})-0.44(\mathrm{SSH})-0.11(\mathrm{KH})-0.87(\mathrm{WoB}) \\
& \mathrm{L}_{3}=-1.06(\mathrm{PFH})-0.10(\mathrm{BPL})-0.12(\mathrm{ESH})-0.04(\mathrm{SSH})+0.26(\mathrm{KH})-0.63(\mathrm{WoB})
\end{aligned}
$$


In multivariate analyses, structure coefficients increase in importance when the observed variables in the model increase in their correlation with each other. Explanation of both standardized weights and structure coefficients are necessary for understanding variable importance in a canonical correlation analysis. For emphasis, structure coefficients above 0.45 and communalities above $45 \%$ are also underlined to show the variables with the highest level of usefulness in the model (Courville\& Thompson, 2001).

In Table 4, the first canonical variable showed that, sitting shoulder height and width of bitrochanter (anthropometric variables) were the primary contributors to the predictor synthetic variable, and seat width contributed to criterion synthetic variable. Because the structure coefficient for sitting shoulder height was negative, it was negatively related to the furniture variable. However, because the structure coefficient of width of bitrochanter was positive, it was positively related to the furniture variable. Canonical variable 2 suggests that the criterion variables of importance were seat width and desk clearance. As for anthropometric variables, only width of bitrochanter was a relevant predictor. Because the structure coefficient for width of bitrochanter was negative, it was negatively related to all the furniture variables. Canonical variable 3 suggests that the only criterion variable of relevance was seat height. As is apparent, popliteal to floor height was the only relevant predictor to predictor synthetic variable. Because the structure coefficient for popliteal to floor height was negative, it was positively related to the furniture variable.

\section{Conclusion}

Multivariate method is about putting together many variables within a single research analysis. Sitting shoulder height and width of bitrochanter are negatively and positively related with seat width respectively. Also, width of bitrochanter is negatively related with both desk clearance and seat width. Furthermore, popliteal to floor height is positively related with seat height. Therefore, canonical correlation analysis has been used to develop relationship between anthropometric measurements and furniture measurements to enhance some healthy sitting posture.

\section{Acknowledgements}

The authors gratefully acknowledge the support of the staff and facilities of the participating institutions, Kumasi Technical University, Ministry of Lands and Natural Resources and Kwame Nkrumah University of Science and Technology.

\section{References}

Abeysekera, J.D.A. (1985). Design requirements and dimensions for a comfortable work seat for Sri Lankans. J. Natn. Sci. Coun; 13 (1): $77-88$

Adu, G. (2017). Ergonomics of office chair design, anthropometry and health mix: a case study of administrative staff in public institutions in Kumasi. PhD thesis, Kwame Nkrumah University of Science and Technology, Kumasi, Ghana.

Bartoszynski, R. and Niewiadomska-Bugaj, M. (2008). Probability Statistical Inference, 2nd ed. Hoboken, New Jersey: Wiley-Interscience, 663Pp.

Bolstad, G., Benum, B. and Rokne, A. (2001). Anthropometry of Norwegian light industry and office workers, Applied Ergonomics; 32(3): 239-246.

Courville, T. and Thompson, B. (2001). Use of structure coefficients in published multiple regression articles: $\beta$ is not enough. Edu. and Psych. Meas., 61: $229-248$.

Del Prado-Lu, J.L. (2007). Anthropometric measurement of Filipino manufacturing workers. International Journal Industrial Ergonomics; 37: 497-503.

Garcia-Acosta, G. and Lange-Morales, K. (2007). Definition of sizes for the design of school furniture for Bogotá schools based on anthropometric criteria. Ergonomics; 50 (10): 1626-1642.

Gunderson, B.K. and Muirhead, R.J. (1997). On estimating and dimensionality in canonical correlation analysis. J. Multivariate Anal., 62: $121-136$.

Johnson, R.A. and Wichern, D.W. (2007). Applied Multivariate Statistical Analysis, 6th ed. Upper Saddle River, New Jersey: Pearson Prentice Hall, 794Pp.

Pheasant, S. (2003). Body space: Anthropometry, Ergonomics and the Design of Work, $2^{\text {nd }}$ ed., Taylor \& Francis, London, UK, 244Pp.

Sheskin, D.J. (2000). Handbook of Parametric and Nonparametric Statistical Procedures, $2^{\text {nd }}$ ed., Boca Raton, Florida: Chapman \& Hall/CRC, 856Pp.

Thompson, B. (1984). Canonical correlation analysis: uses and interpretation. Sage Publication, California, pp. 69.

Wang, M.J., Wang, E.M.Y. and Lin, Y.C. (2002). Anthropometric database for children and young adults in Taiwan, Applied Ergonomics; 33: $583-585$.

Wilkinson, L. and APA Task Force on Statistical Inference (1999). Statistical methods in Psycho. J. Guidelines and explanations. American Psychologist, 54: $594-604$. 